\title{
Estudo da flutuação populacional da mosca-do-botão-floral no maracujazeiro-azedo por meio de armadilhas adesivas amarelas
}

\author{
Érica Frazão Pereira De Lorenzi' ${ }^{1}$ Betina Emerick², Daniel Remor Moritz ${ }^{3}$ e Henrique Belmonte Petry ${ }^{4}$
}

Resumo - O objetivo deste trabalho foi avaliar a flutuação populacional da mosca-do-botão-floral no maracujazeiro-azedo e a eficiência de armadilhas adesivas amarelas na captura da praga em diferentes alturas em relação ao nível do solo. Na safra 2017/18 foram instaladas armadilhas adesivas amarelas a diferentes alturas (1 e $2 \mathrm{~m}$ ) em pomares de maracujazeiro-azedo, com áreas entre um e dois hectares situados em diferentes municípios produtores dos estados de Santa Catarina e do Rio Grande do Sul. A armadilha adesiva amarela foi eficiente na captura da praga sendo a altura de $2 \mathrm{~m}$ a mais representativa. 0 pico populacional da praga ocorreu no mês de novembro e os municípios com maior infestação foram Araquari e Sombrio, em Santa Catarina e em Torres, no Rio Grande do Sul. Estudos mais aprofundados são necessários para que se possa recomendar um nível de controle a partir do número de moscas capturadas/armadilha/período.

Termos para indexação: Lonchaeidae; pico populacional; cartões adesivos, maracujá; Diptera.

\section{Study of the population fluctuation of the flower bud fly in the passion fruit through yellow sticky traps}

Abstract - The objective of this work were to evaluate the population fluctuation of the sour passion fruit flower bud fly and the efficiency of yellow sticky traps in the capture of the pest at different heights from the soil level. In the 2017/18 season, yellow sticky traps were installed at different heights $(1$ and $2 \mathrm{~m})$ adjacent to sour passion fruit orchards, of one to two hectares, located in different producing municipalities of the State of Santa Catarina and Rio Grande do Sul, Brazil. The yellow sticky traps were efficient in catching the pest, being the height of $2 \mathrm{~m}$ the most representative. The pest peak population occurred in November and the municipalities with the highest pest infestation were Araquari and Sombrio, Santa Catarina and Torres, Rio Grande do Sul. Further studies are needed so that a level of control can be recommended from the number of captured flies / trap / period.

Index terms: Lonchaeidae; Population Peak; Sticky Cards; Passion fruit; Diptera.

O cultivo do maracujazeiro-azedo (Passiflora edulis Sims.) em Santa Catarina tem se destacado pela produção de alta qualidade e pela oferta em época de grande demanda pelo consumidor, nos meses de verão, tornando-se uma atividade rentável para os agricultores familiares do litoral catarinense. A produção de maracujá tem se consolidado entre as frutas mais produzidas no estado (EPAGRI, 2019), que foi o terceiro maior produtor do Brasil em 2017 (IBGE, 2019).

Uma diversidade de espécies de insetos e ácaros visitam o maracujazeiroazedo. No entanto, poucas são consideradas pragas-chave, capazes de causar prejuízos, que justificam a adoção de estratégias de manejo para redução de seus danos. Muitas espécies têm ocorrência esporádica e/ou em baixos níveis populacionais, sendo vistas como pragas secundárias (OLIVEIRA \& FRIZZAS, 2014).

A partir da safra 2015/16, produtores do Extremo Sul catarinense começaram a observar abortamento intenso de botões florais no maracujazeiro-azedo, o que, após investigação laboratorial, foi associado à presença de larvas de um díptero identificado como Dasiops sp., cujo nome comum é mosca-do-botãofloral (Diptera: Lonchaeidae) (PEREIRA et al., 2017).

Entre as diversas pragas que promovem danos ao maracujazeiro a mosca-do-botão-floral vem apresentando grande importância principalmente devido aos danos das larvas aos botões florais. A postura da fêmea adulta da mosca é realizada na base do botão floral, que geralmente fica com uma mancha marrom, fazendo com que o botão possa adquirir aspecto enrugado e perda do brilho das sépalas (GALINDO et al., 2013). As larvas permanecem no interior do botão consumindo as anteras e o ovário, promovendo sua queda e, consequentemente, perda de produção quando em alta infestação (LEMOS et al., 2015).

Os adultos da mosca-do-botão-floral medem de 4 a $9 \mathrm{~mm}$ de comprimento, possuem coloração preta brilhante com reflexos metálicos de tons azulados ou esverdeados, asas transparentes e sem manchas (BOIÇA JÚNIOR, 1998; LUNZ et al., 2006) (Figura 1 A). As larvas são ápodas, esbranquiçadas e do tipo vermiforme, medindo cerca de $7 \mathrm{~mm}$ de comprimento (BOIÇA JÚNIOR, 1998). Quando chegam ao último estádio de desenvolvimento normalmente as larvas saltam

Recebido em 3/7/2019. Aceito para publicação em 7/10/2019.

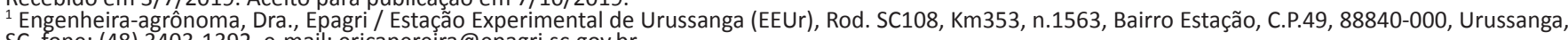
SC, fone: (48) 3403-1392, e-mail: ericapereira@epagri.sc.gov.br.

2 Acadêmica do Curso de Ciências Biológicas, Unesc. E-mail: betina.emerick@hotmail.com.

${ }^{3}$ Engenheiro-agrônomo, Mestrando em Fitotecnia, Cidasc. E-mail: daniel@cidasc.sc.gov.br.

${ }^{4}$ Engenheiro-agrônomo, Dr., Epagri / EEUr. E-mail: henriquepetry@epagri.sc.gov.br. 
dos botões florais para empupar no solo (OLIVEIRA \& FRIZZAS, 2014).

As perdas na produção associadas à mosca-do-botão-floral podem chegar a $100 \%$, sendo relacionadas principalmente à espécie Dasiops inedulis (LUNZ et al., 2006; AGUIAR-MENEZES et al., 2004).

Em Santa Catarina os produtores vêm buscando a antecipação da produção para a obtenção de melhores remunerações junto ao mercado consumidor. Para isso, procuram plantar mudas grandes (maiores que $80 \mathrm{~cm}$ ) produzidas em ambiente protegido e que poderão florescer pelo menos quinze dias antes (SÔNEGO et al., 2017). A primeira florada do maracujazeiro produz frutos de maior valor comercial (PIEVA et al., 2017), sendo este momento economicamente o mais importante no caso de altos índices populacionais da praga. Diante disso, monitorar a época de ocorrência da mosca-do-botão-floral no maracujazeiro e determinar seus picos populacionais desde o início da safra são medidas fundamentais para estabelecer estratégias de manejo da praga.

O método para monitoramento da mosca-do-botão-floral não está determinado e, de acordo com Carvalho et al. (2015), devido a essa lacuna de conhecimento, pode ser possível adotar a mesma recomendação para monitoramento de moscas-das-frutas. Carvalho \& Macedo (2015) indicam para monitoramento e controle de mosca-das-frutas o uso de 1 a 2 armadilhas por hectare, do tipo McPhail ou produzidas com garrafas PET, contendo proteína hidrolisada, melaço de cana a $7 \%$ ou suco de frutas (exceto o de maracujá) com $10 \mathrm{~g}$ de bórax, realizando-se avaliações semanais e trocas quinzenais.

Nesse trabalho objetivou-se determinar a flutuação populacional da mosca-do-botão-floral no maracujazeiro-azedo em diferentes municípios produtores do estado de Santa Catarina por meio de armadilhas adesivas amarelas de modo a avaliar sua eficiência como ferramenta de monitoramento.

Na safra 2017/18 foram selecionados pomares entre um e dois hectares nos municípios de Antônio Carlos, Araquari, Araranguá, Governador Celso Ramos, Içara, Jacinto Machado, Pedras Grandes, Praia Grande, Santa Rosa do
Sul, São João do Sul, Sombrio e Torres. Numa das bordaduras desses pomares e sob influência do vento predominante, foram instaladas duas armadilhas adesivas amarelas (10 x 15cm), uma a $1,0 \mathrm{~m}$ e outra a $2,0 \mathrm{~m}$ de altura (Figura $1 \mathrm{~B})$, acima da linha do arame de condução das plantas, sendo realizadas as trocas quinzenais. As armadilhas etiquetadas foram triadas em laboratório, e os lonqueídeos capturados foram quantificados. Posteriormente foi realizada análise estatística descritiva para avaliação dos resultados obtidos, e teste de qui-quadrado para determinar a melhor posição das armadilhas no pomar para captura das moscas.

Durante todo o período de levantamento foram avaliadas 203 armadilhas adesivas. O pico populacional de lonqueídeos ocorreu em novembro, considerando o somatório de todos os espécimes capturados nos municípios monitorados (Figura 2 A). Houve diferença significativa entre as alturas avaliadas ( $p$ =0,997), em todo o período avaliado, com maior número de lonqueídeos capturados na posição superior $(2 \mathrm{~m})$, com probabilidade de erro menor que $0,1 \%$, pelo teste de qui-quadrado.

O pico populacional da mosca em novembro coincide com as primeiras floradas do maracujazeiro-azedo na re- gião do litoral sul de Santa Catarina e norte do Rio Grande do Sul. Considerando que a colheita dos frutos pelos agricultores do estado ocorre em um período quando a maioria dos demais estados brasileiros produtores da fruta ainda não entraram em produção, o pico populacional da praga em novembro representa risco de prejuízo ao agricultor catarinense, já que a produção de frutos precoces garante uma boa renda aos produtores da região.

O maior índice de captura na altura superior indica que a praga chega aos pomares migrando de áreas vizinhas, devendo-se atentar às culturas presentes no entorno. Caso também sejam hospedeiras de lonqueídeos - como é caso da cultura da mandioca, cuja região sul catarinense é a principal produtora em Santa Catarina - faz-se necessário que o manejo desta praga na cultura do maracujazeiro-azedo deva ser pensado de modo integrado ao manejo da mosca-do-broto na cultura da mandioca.

Houve variação entre os municípios estudados quanto à incidência média de mosca-do-botão-floral (Figura 2 B) no período de maior incidência da praga, entre os meses de outubro e dezembro. As armadilhas adesivas amarelas foram eficientes para capturar os lonqueídeos em todos os locais monitorados, apesar

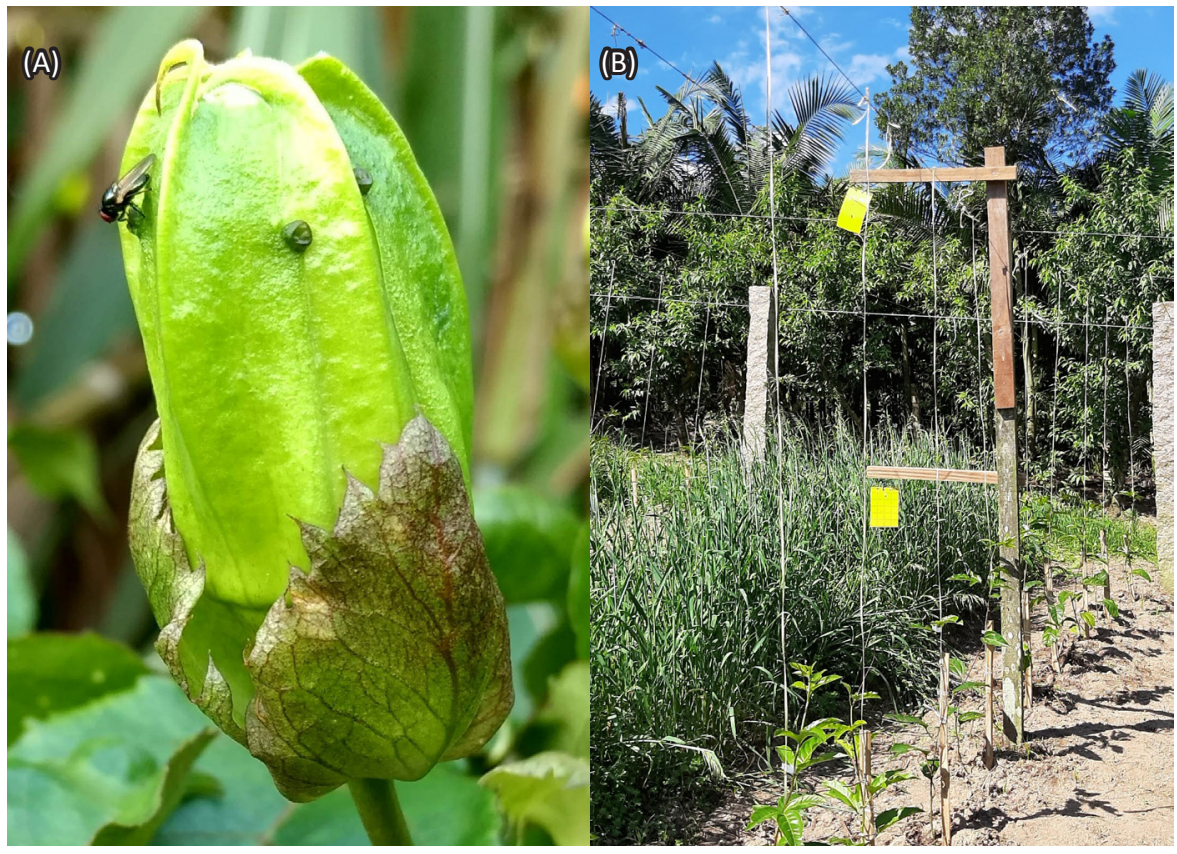

Figura 1. Mosca-do-botão-floral-do-maracujazeiro adulta (A) e posicionamento das armadilhas adesivas amarelas em diferentes alturas (B). Foto: Érica Frazão Pereira Figure 1. Adult passionflower flower bud fly $(A)$ and positioning of yellow sticky traps at different heights (B). Photo: Érica Frazão Pereira 


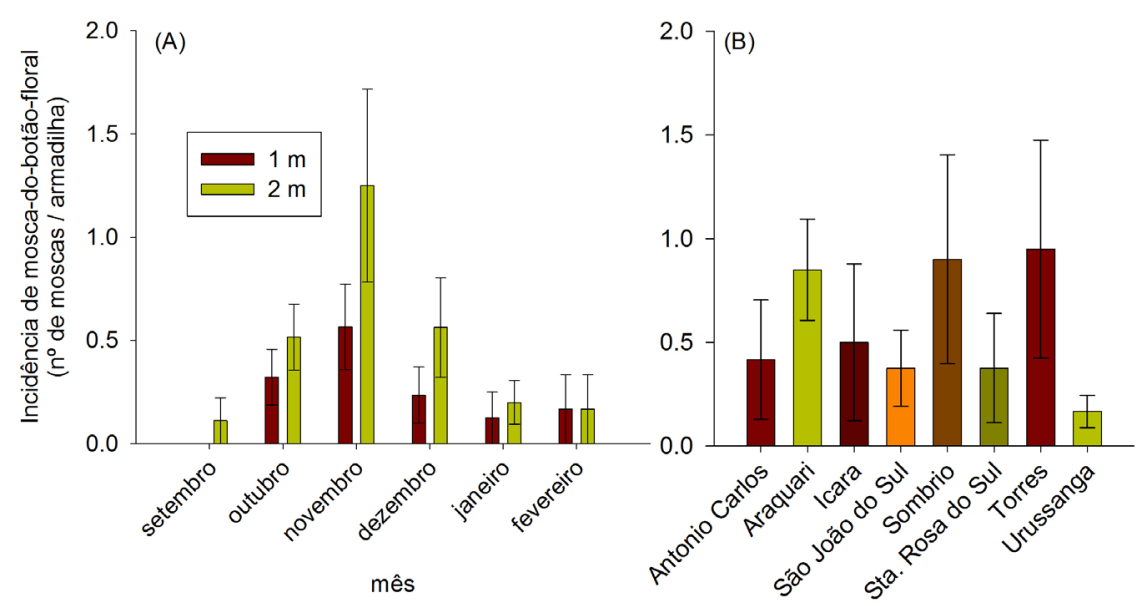

Figura 2. Incidência de moscas-do-botão-floral-do-maracujazeiro capturadas por armadilhas adesivas amarelas em diferentes alturas, entre os meses de setembro e fevereiro (A), e em pomares de maracujazeiro-azedo de diferentes municípios produtores dos estados de Santa Catarina e do Rio Grande do Sul, média dos meses de outubro a dezembro, durante a safra 2017/18 (B)

Figure 2. Incidence of passionflower flower bud flies caught by yellow sticky traps at different heights between September and February $(A)$ and in sour passion fruit orchards from different producing municipalities in the states of Santa Catarina and Rio Grande do Sul, from October to December, during the $2017 / 18$ season (B)

da variabilidade observada. Esta variação pode ser atribuída a diversos fatores de manejo dos pomares, visto que comercialmente os agricultores utilizam cama de aves como fertilizante orgânico no período de plantio e crescimento do maracujazeiro-azedo, que pode atuar como atrativo para estas moscas (McALPINE, 1987). Além disso, o uso de inseticidas, principalmente piretroides, pode ter influenciado na captura das moscas ao longo do período avaliado, manejo este que variou de acordo com as indicações para cada pomar.

Portanto, maiores populações da mosca-do-botão-floral em Santa Catarina são observadas entre os meses de outubro e dezembro, e armadilhas adesivas amarelas possuem potencial de uso no monitoramento desta praga no maracujazeiro-azedo, sendo a altura de $2 \mathrm{~m}$ a mais indicada. Estudos mais detaIhados comparando diferentes métodos de monitoramento associados à avaliação de nível de dano precisam ser realizados para uma recomendação de uso das armadilhas adesivas amarelas para o monitoramento desta praga.

\section{Agradecimentos}

Os autores agradecem todos os técnicos em extensão da Epagri dos muni- cípios que participaram desse estudo bem como os produtores que permitiram o levantamento em suas propriedades.

\section{Referências}

AGUIAR-MENEZES, E.L.; NASCIMENTO, R.J.; MENEZES, E.B. Diversity of fly species (Diptera: Tephritoidea) from Passiflora spp. and their hymenopterous parasitoids in two municipalities of the southeastern Brazil. Neotropical Entomology, v.33, n.1, p.113-116, 2004.

BOIÇA JÚNIOR, A.L. Pragas do maracujá. In: RUGGIERO, C. (Ed.). Maracujá: do plantio à colheita. Jaboticabal: Unesp, 1998. p. 175207.

CARVALHO, R.S.; MACEDO, L.R. Guia para reconhecimento dos principais insetos e ácaros praga e inimigos naturais em citros. Cruz das Almas, BA: Embrapa Mandioca e Fruticultura, 2015, 50p.

CARVALHO, S.L.C. de; STENZEL, N.M.C.; AULER, P. A. M. Maracujá-amarelo: recomendações técnicas para cultivo no Paraná. Londrina, PR: lapar, Boletim Técnico, n. 83, 2015, 54p.

GALINDO, M.Y. S.; ÁVILA, A.P. C.; RAVELO, E.E.E.; BROCHERO, H.L.M. Caracterización de moscas del género Dasiops (Diptera: Lonchaeidae) em Passiflora spp. (Passiflorace- ae) cultivadas en Colombia. Revista Facultad Nacional de Agronomía Medellín, Medellín, v. 67, n. 1, p. 7151-7162, 2014.

EPAGRI. Números da agropecuária catarinense - 2019. Florianópolis, SC, 2019. 65p. (Epagri. Documentos, 291). Disponível em: <http://docweb.epagri.sc.gov.br/website_ cepa/publicacoes/Numeros_Agropecuaria_ Catarinense_maio_2019_site.pdf $>$. Acesso em: 14 out. 2019.

PIEVA, D.C.; ELIAS, H.T.; GUGEL, J.T.; GOULART JÚNIOR, R. Relatório de Mercado Agrícola na Ceasa/SC - Maio/2017 - n.6. Relatório. 2017. Disponível em: http://docweb. epagri.sc.gov.br/website_cepa/Relatorio_ Ceasa/Relatorio_Mercado_Agricola_Ceasa_ Mai_2017_n6.pdf. Acesso em: 12 set. 2017.

IBGE. Produção Agrícola Municipal (vários anos) Rio de Janeiro: IBGE, 2019.

LEMOS, L.N; ADAIME, R.; COSTA-NETO, S.V.; DEUS, E.G.; JESUS-BARROS, C.R.; STRIKIS, P.C. New findings on Lonchaeidae (Diptera: Tephritoidea) in brazilian Amazon. Florida Entomologist, v.98, n.4, p.1227-1237, 2015.

LUNZ, A. M.; SOUZA, L. A.; LEMOS, W. P. Reconhecimento dos principais insetos-praga do maracujazeiro. Belém, PA: Embrapa Amazônia Oriental, 2006, 36p.

MCALPINE, J.F. LONCHAEIDAE. In: MCALPINE, J.F.; PETERSON, B.V.; SHEWELL, G.E.; TERKEY, H.J.; VOKEROTH, J.R.; WOOD, D.M. (Eds.) Manual of Neartic Diptera. Otawa, Canada: Agriculture Canada Monograph, Cap. 62, V.2, p.791-797, 1987.

OLIVEIRA, C.M.; FRIZZAS, M.R. Principais pragas do maracujazeiro amarelo (Passiflora edulis f. flavicarpa Degener). Planaltina, DF: Embrapa Cerrados, 2014, 43p.

PEREIRA, B.E.; DE LORENZI, E.F.P.; HARTERMARQUES, B. Primeiro registro de Dasiops spp. Rondani (1856) (Diptera: Lonchaeidae) em pomar comercial de Passiflora edulis Sims. (Passifloraceae) no Sul de Santa Catarina, Brasil. In: SIMPÓSIO BRASILEIRO SOBRE A CULTURA DO MARACUJAZEIRO, 7., 2017, Balneário Arroio do Silva, SC. Anais[...] Florianópolis, 2017.

SÔNEGO, M.; BRANCHER, A.; PERUCH, L.A.M.; PETRY, H.B. Efeito do tamanho de muda de plantio sobre a produção do maracujá-azedo em clima subtropical. In: SIMPÓSIO BRASILEIRO SOBRE A CULTURA DO MARACUJAZEIRO, 7., 2017, Balneário Arroio do Silva, SC. Anais[...] Florianópolis, 2017. 